\title{
Inversión en ciencia y tecnología motor de desarrollo...
}

\author{
Jorge Hernando Bautista Ruiz, M.Sc.
}

Docente UFPS

El desarrollo de las naciones más sobresalientes se ha basado en la inversión de recursos en educación, investigación y desarrollo; bajo esta premisa muchos países han comprendido que el grado de crecimiento es proporcional a su inversión en Ciencia y Tecnología. Según cifras del Banco Mundial en latinoamerica los países con altos índices de desarrollo son: Brasil que asigna el 1,2\% de su PIB y Argentina el 0,6\%, mientras Colombia realiza una inversión del $0,2 \%$ del PIB, la cual permite evidenciar la brecha existente en los indicadores en materia de Ciencia, Tecnología y desarrollo industrial.

Como agravante a esta situación Colombia cada año reduce el presupuesto para Ciencia y Tecnología; dicha disminución presupuestal no es nueva, año tras año, la comunidad científica pone de manifiesto su descontento ante tal realidad. Ello trae a la memoria las conclusiones que en Medellín en el año 2014, se consolidaron en la reunión del denominado G8 (Grupo de Universidades de Medellín) y que recogen los anhelos de la mayoría de los científicos colombianos,... "la adopción de una política de Estado que favorezca el desarrollo de la ciencia y la tecnología, sólida, consistente y de largo plazo. Este tipo de politicas fue propuesto en Colombia desde la Misión de los Sabios hace 20 años. Luego fue ratificada en documentos CONPES y posteriormente en algunos intentos de proyectos de ley. Se trata de medidas adoptadas exitosamente por países como Israel, Alemania, Italia, Bélgica, Corea, Malasia, y Singapur, donde la innovación basada en conocimiento les ha permitido aumentar su competitividad en el mundo globalizado, asegurar economías estables y mejorar el empleo, entre otros".

Esta menor cantidad de recursos destinados por Colombia al desarrollo científico por parte de los entes gubernamentales, dejan entrever que no han avisorado que el crecimiento sostenible del país y su desarrollo económico y social radican en sostener una industria competitiva e innovadora, la cual demanda del desarrollo de la investigación y la innovación. Con esta estrategia Colombia podrá contar con una industria fortalecida desde lo científico y lo tecnológico para desarrollar su capacidad de competir a escala regional y mundial, con productos y servicios que representen un alto valor agregado y así hacer frente a los retos que imponen los tratados de libre comercio que se han firmado.

Ante tal situación, el gobierno pretende que los recursos faltantes sean obtenidos a través de las regalías, las cuales se consideran insuficientes para financiar el desarrollo de la Ciencia y la Tecnología del país, como lo afirma Dolly Montoya, Directora de Investigaciones de la Universidad Nacional.. "...hasta el momento los proyectos de regalías son de innovación social y algunos de innovación tecnológica, pero la ciencia básica, que es la que genera el conocimiento, no está comtemplada en esas iniciativas..." y amplía afirmando que “...con parte de los recursos de regalias se hace capacitación de alto nivel, que es muy importante, pero si no invertimos en generación de conocimiento nos ubicaremos al final de la cadena..." refiriéndose a la cadena investigativa que comprende tres estadios: el primero, relacionada con la ciencia básica, el segundo con investigación y desarrollo, y el último estadio relacionado con la innovación.

Dichos estadios se deben propiciar, de lo contrario los resultados investigativos que pueda mostrar el país no serán suficientes en un mundo globalizado, donde el crecimiento se mide por el grado de desarrollo en Ciencia y Tecnología; el cual es muy anhelado por la comunidad científica del país que esperanza algún día sea realidad en un futuro no muy lejano, donde el gobierno considere como eje fundamental del desarrollo de Colombia, la inversión en Ciencia y Tecnología, entre tanto se esperaría que no siga disminuyendo el prespuesto asignado a la ciencia. 